\title{
A knowledge-based decision support system for government vendor selection and bidding
}

\author{
Wei-Kang Wang ${ }^{1}$, Wu Wen ${ }^{2}$, W. B. Chang ${ }^{2}$, Hao-Chen Huang ${ }^{3}$ \\ ${ }^{I}$ Department of Accounting, Yuan-Ze University, Taiwan, R.O.C. \\ ${ }^{2}$ Department of Information Management, LungHwa University of Science and Technology, Taiwan, \\ R.O.C. \\ ${ }^{3}$ Graduate Institute of Business Administration, National Taiwan University, Taiwan, R.O.C.
}

\begin{abstract}
In this paper, we present a new framework for knowledge-based decision support systems for government vendor selection and bidding. The system integrates a database, rule base and model base as a tool for managers in the decision-making problems via the Internet. The procurement procedures for and architecture of the government vendor selection and bidding in Taiwan are discussed in detail. Particularly, rules in the rule base are explained in more detail for illustrating the process of reasoning and KDSSVSB adapts to quickly and accurately infer and generate suggestions or actions. In order to evaluate suppliers' qualifications, the AHP and Non-AHP model in the model base have been developed. Finally, the empirical functions of the KDSSVSB system are also addressed and a bidding case is presented.
\end{abstract}

Keywords: Vendor selection and bidding; knowledge-based decision support systems; Knowledge bases; Model bases; Forward reasoning

\section{Introduction}

Growth in ROC government procuring has been significant over the past several years. The total government procurement was NT\$ 532 billion in FY 2002 and NT\$694 billion in 2003, an increase of NT\$ 162 billion. The growth rate was $30.4 \%$. Thus, government agencies have been focusing on the purchasing process. Government purchasing is guided by the twin policy objectives of achieving the best value for money and maintaining open and fair competition. These two sets of objectives are complementary: by encouraging participation through open, fair, and transparent procurement procedures and practices, the government obtains responsive and competitive vendors among which it can determine the most advantageous one which best serves the interests of Taiwan's people.

However, government vendor selection decisions in today's increasingly complex, competitive global environment are inherently multi-objective in nature. Increased demands on, and expectations of, a firm's suppliers create the need for careful analysis of supplier selection and volume allocation decisions. Yet the decision process must still take into account trade-offs, which likely exist among key criteria in supplier selection. Because of the complexity and importance of supplier selection decisions, decision support systems are frequently used as tools to support decision-making. Therefore, developing an e-procurement via a web-based architecture for government use is a big challenge. Thus, for the above reasons, we have developed a Knowledge-based Decision Support System (KDSSVSB) for vendor selection to provide and refresh real-time information which decision-making officers can use to quickly and accurately infer and generate suggestions or actions.

Decision support systems are computerbased tools that aid the managerial decisionmaking process by presenting various effective alternatives. By using forward reasoning and knowledge rules, the system can automatically change and regenerate a national defense budget plan immediately. The analysis of criteria for supplier selection and performance measurement has been the focus of many academicians and purchasing practitioners since the 1960s. With the increase and maturation of information technology, and the growth in the popularity of the Internet, these techniques provide opportunities to enhance techniques for knowledge-based expert systems (KES) and decision support systems (DSS) and help managers tackle fast-changing business markets.

\section{Vendor selection criteria}

The selection of competent suppliers has long been regarded as one of the most important functions to be performed by a purchasing department. However, vendor selection decisions are complicated by the fact that various criteria must be considered in the decision making process. The analysis of criteria for selecting vendors and measuring their performance has been a subject of interest for many academicians and purchasing practitioners since the 1960's. Dickson( 1966 )suggests: "From 
the purchasing literature, it is fairly easy to abstract a list of at least 50 distinct factors (characteristics of vender performance) that are presented by various authors as being meaningful to consider in a vender selection decision".

The Dickson study was based on a questionnaire sent to 273 purchasing agents and managers selected from the membership list of the National Association of Purchasing Managers. The list included purchasing agents and managers from the United States and Canada. Table 1 summarizes the findings of Dickson's study regarding the importance of the 23 criteria for vendor selection.

Monczka and Trecha (1988)classify supply strategies as one of the strategic operations choices. Additionally, with the increase in use of total quality management (TQM) and just-in-time (JIT) concepts by a wide range of firms, the supplier selection question has become extremely important. Senter Jr., and Flynn, [24] found supplier involvement to be an important dimension of quality management. Benton and Krajewski (1990) classify the supplier selection process as an important operations management (OM) decision area. They suggest that OM research should attempt to identify the supply chain management practices that provide competitive advantage. Karmarkar (1989) also identifies supply chains as multi-disciplinary in nature and recommends an integrated OM/marketing approach. Cardozo and Cagley (1971), Chapman (1989), Dempsey (1978), Hakansoon and Wootz (1975), Monczka et al. (1998), and several other authors have evaluated the relative importance of quality, cost, delivery performance, and other supplier attributes. In summary most of the articles referenced above suggest that managers should not select suppliers based on low cost only but should consider quality, delivery performance and other attributes. In this paper, we adopt the AHP analysis to select qualified vendors.

Table 1 Dickson's vendor selection criteria

\begin{tabular}{|c|c|c|c|}
\hline Rank & Factor & $\begin{array}{c}\text { Mean } \\
\text { Ranking }\end{array}$ & Evaluation \\
\hline 1. & Quality & 3.508 & \multirow[t]{4}{*}{$\begin{array}{l}\text { Extreme } \\
\text { importance }\end{array}$} \\
\hline 2. & Delivery & 3.417 & \\
\hline 3. & Performance History & 2.998 & \\
\hline 4. & $\begin{array}{l}\text { Warranties and } \\
\text { Claim Policies }\end{array}$ & 2.849 & \\
\hline 5. & $\begin{array}{l}\text { Production Facilities } \\
\text { and Capacity }\end{array}$ & 2.775 & \multirow[t]{5}{*}{$\begin{array}{l}\text { Considerable } \\
\text { importance }\end{array}$} \\
\hline 6. & Price & 2.758 & \\
\hline 7. & Technical Capability & 2.545 & \\
\hline 8. & Financial Position & 2.514 & \\
\hline 9. & $\begin{array}{l}\text { Procedural } \\
\text { Compliance }\end{array}$ & 2.488 & \\
\hline
\end{tabular}

\begin{tabular}{|c|c|c|c|}
\hline 10. & $\begin{array}{l}\text { Communication } \\
\text { System }\end{array}$ & 2.426 & \\
\hline 11. & \begin{tabular}{|l|} 
Reputation and \\
Position in Industry
\end{tabular} & 2.412 & \\
\hline 12. & Desire for Business & 2.256 & \\
\hline 13. & $\begin{array}{l}\text { Management and } \\
\text { Organization }\end{array}$ & 2.216 & \\
\hline 14. & Operating Controls & 2.211 & \\
\hline 15. & Repair Service & 2.187 & \multirow[t]{8}{*}{$\begin{array}{l}\text { Average } \\
\text { importance }\end{array}$} \\
\hline 16. & Attitude & 2.120 & \\
\hline 17. & Impression & 2.054 & \\
\hline 18. & Packaging Ability & 2.009 & \\
\hline 19. & $\begin{array}{l}\text { Labor Relations } \\
\text { Record }\end{array}$ & 2.003 & \\
\hline 20. & $\begin{array}{l}\text { Geographical cal } \\
\text { Location }\end{array}$ & 1.872 & \\
\hline 21. & $\begin{array}{l}\text { Amount of Past } \\
\text { Business }\end{array}$ & 1.597 & \\
\hline 22. & Training aids & 1.537 & \\
\hline 23. & \begin{tabular}{|l} 
Reciprocal \\
Arrangement
\end{tabular} & 0.610 & \begin{tabular}{|l}
$\begin{array}{l}\text { Slight } \\
\text { importance }\end{array}$ \\
\end{tabular} \\
\hline
\end{tabular}

\section{Architecture of the knowledge -based DSS for vendor selection and bidding}

The architecture of the decision support system for vendor selection and bidding is presented in Fig. 1. The primary components are as follows: a database, a rule base, and a model base with an AHP model. Through a convenient e-procurement Internet-based system, a government agency can review and evaluate vendors fairly and publicly. Basically, domain experts grant the scores of weights based on their experiences and own judgments. Evaluation factors are composed of performance, manpower, financial resources and equipment. Finally, the system adopts an Analytic Hierarchy Process (AHP) model and knowledge reasoning to select the qualified vendors.

First of all, vendors get bidding-invitation information through bidding-invitation announcements. Then, they can submit bids and pay earnest money by means of e-transfer. Next, suppliers can download an e-invitation-bid form through an online e-procurement system. They should send electronic bid-inviting documents via the Internet before a deadline. The government agency keeps all tendering information in the database. For fairness, every time the bidding unit shall announce all evaluating factors and weights assessed by domain experts. In order to perform the review process successfully, the system needs to check all vendors' identification and basic data from a historical database. If the vendor does have not any records in the database, an Internet-based search engine or traditional phone to connect 
banks or associations will be used to check whether the vendors' documents are true and qualified. Once the vendor's basic qualification and data are validated, the AHP model is adopted to select the final qualified vendors to participate Internet-based bidding via E-mail. In the bid-invitation period, agency examines valid bidding forms to compare price. If two or more vendors offer the floor price, the one who offers the lowest price wins the bidding. If no bidder gave the floor price, on-the-site reduced-rate action will be taken, and the winner will go to the bidder who first gives the floor price and the lowest price. After awarding bidding, the results will be announced publicly on the Internet and a contract will be signed within the legally prescribed period.
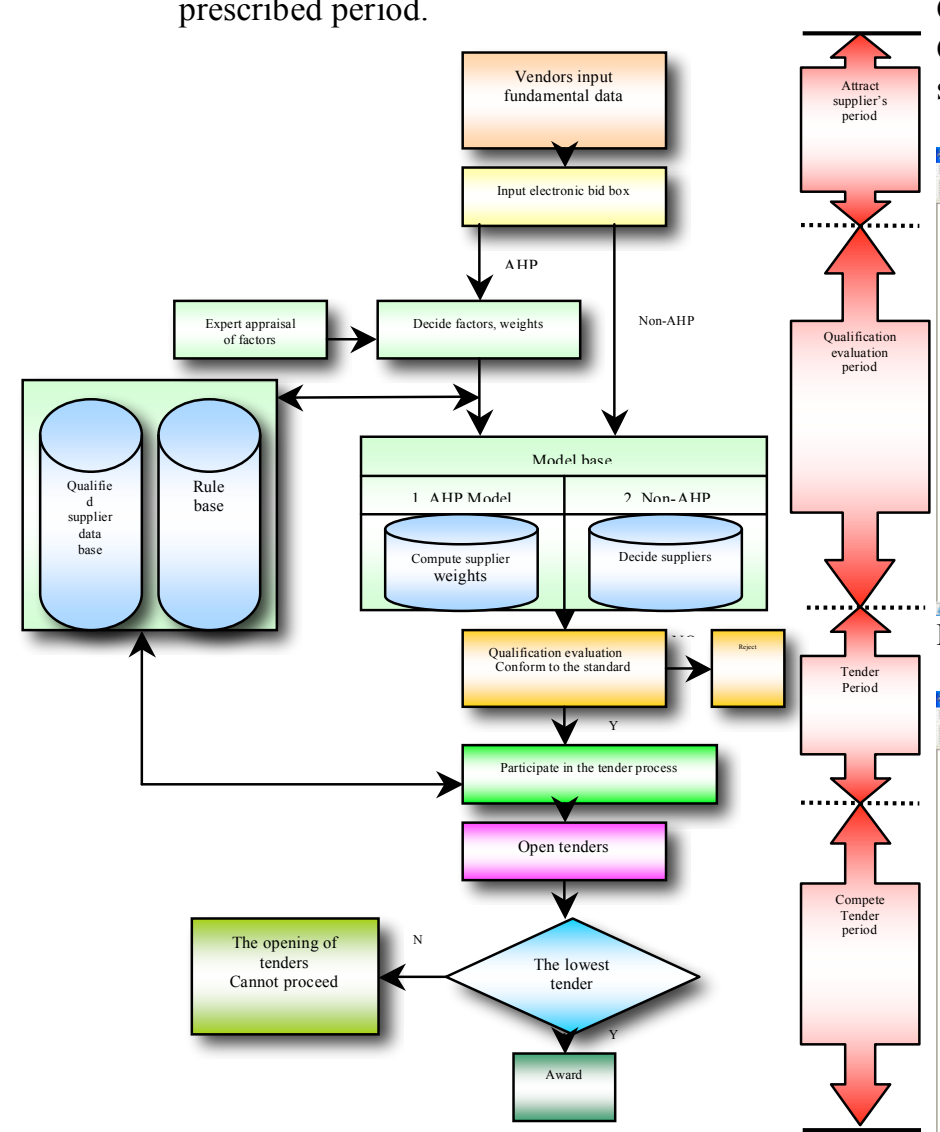

Fig. 1 Architecture of the knowledge-based decision support system for vendor selection and bidding

\section{Implementation of the DSS}

To prove the system's efficiency and practical application, the knowledge-based decision support system for vendor selection and bidding has been built. The main functions of the KDSSVSB system include query, qualification evaluation, expert assessment, and web-based tendering. The first entry of the KBDSSVS is the login menu. Suppliers and the procurement agency are the two main users of the system.
They can assess the system through the Internet and can browse useful information stored in the database. Users must pass the on-line authentication stage of security management. Without registration, users are not allowed to enter the system. Those who are not yet registered may enter the registration system to register. As shown in Fig.2, the Querying Function Menu is used to search for information, including bidder, procurement item name, procurement item no., and category information.

This system provides AHP and Non-AHP models that buyer and bidders can use to evaluate vendor qualifications. The Non-AHP model is used to evaluate individual vendors through Company Name, Sales, ISO Certificated, Quality Assurance, History, Capital, and Credit Ranking information as shown in Fig. 3.

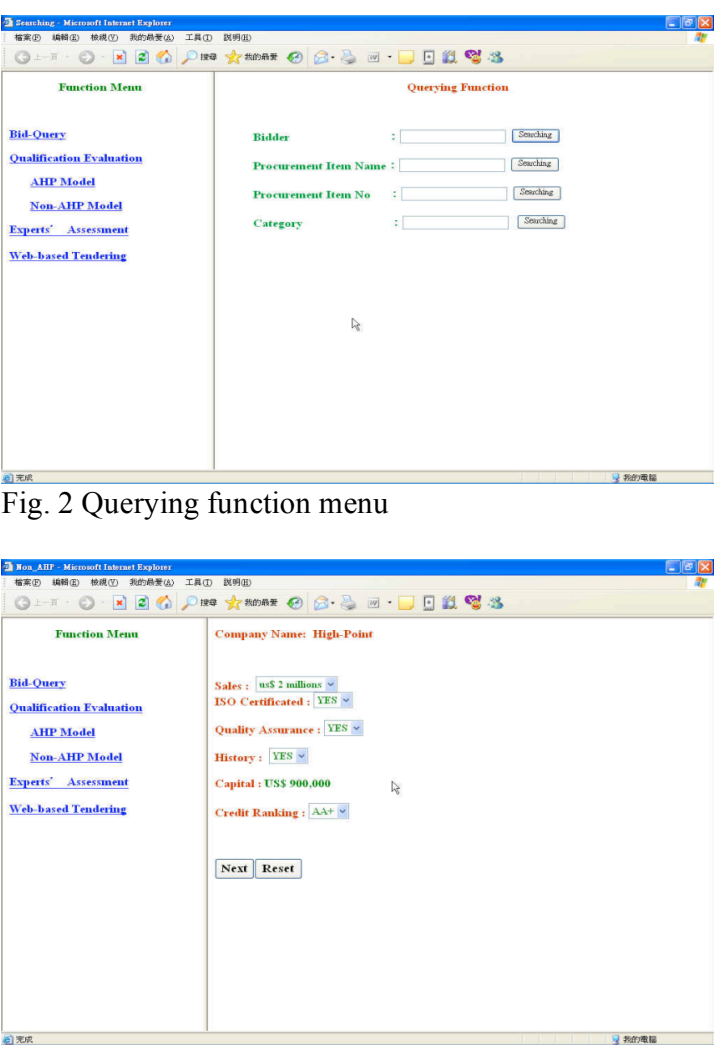

Fig. 3 Non-AHP model menu

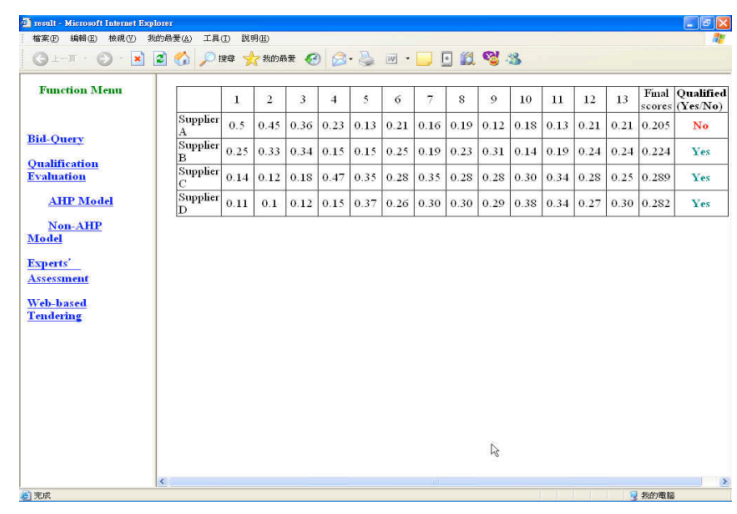


Fig. 4 The final result of AHP analysis for vendor selection

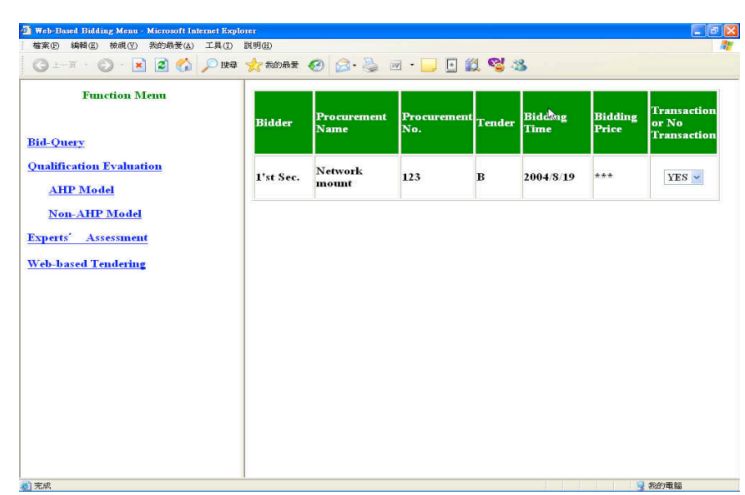

Fig. 5 The result of awarding bidding

We selected 17 experts, 13 from academic institutions and 4 from professional organizations in Taiwan. The chosen experts' amount of experience related to IT averaged 6 years. In the study, pair-wise comparison matrices were obtained at each level of the hierarchy. The EXPERTCHOICE software was used to generate weights. After expert evaluation and the comparison matrix had been completed; we extracted its vector of eigenvalues. These values were used as the weights for the subelements. Following construction, the weights should add up to 1.0 (100 percent) for any group of subelements.

These thirteen final weights are multiplied by the appropriate criteria weights to meeting the goal of the hierarchy. Then, the results of the four multiplications are added together to compute the vendor score. Finally, firms A, B, $\mathrm{C}$, and $\mathrm{D}$ had scores of $\mathrm{A}=0.205, \mathrm{~B}=0.224$, $\mathrm{C}=0.288$, and $\mathrm{D}=0.282$, respectively. Thus, we selected the top three firms, B, C, and D, to join the bidding process, and notified them of the bidding time through e-mail (see Fig. 4).

In the bid-invitation period, the government agency examines valid bidding forms to compare price. If two or more vendors offer the floor price, the one who offers the lowest price wins the bidding. After awarding bidding, the result will be announced publicly on the Internet as shown in Fig. 5, and contract will be signed within the legally prescribed period.

\section{Conclusions and future work}

Government vendor selection decisions in today's increasingly complex, competitive global environment are inherently multi-objective in nature. Therefore, we have developed a Knowledge-based Decision Support System for vendor selection and bidding (KDSSVSB) to provide and refresh real-time information which decision-making officers can use to quickly and accurately infer and generate suggestions or actions. The system integrates a database, rule base and model base as a tool for managers in the decision-making problems via the Internet. Particularly, rules in the rule base are explained in more detail for illustrating the process of reasoning. In order to evaluate suppliers' qualifications, the AHP and Non-AHP model in the model base have been developed. The AHP generator in the system provides the decision-maker with the ability to use his information set and subjective judgments in modeling the qualitative variables.

Although we have developed the KDSSVSB system, there are still several ways in which we can further improve its functions. In light of the nature of vendor selection, multi-objective programming techniques may be included in the future to provide these functions. Such analysis would enable government agency to select the vendors who best satisfy the requirements necessary to implement management strategy.

\section{References}

[1]. Benton, W.C., \& Krajewski, L., "Vendor performance and alternative manufacturing environments", Decision Sciences, 21, 1990.

[2]. Cardozo, R.N., \& Cagley, J.W., "Experimental study of industrial buyer behavior", Journal of Marketing Research VIII, pp. 329-934, 1971.

[3]. Chapman, S.N., "Just-in-time supplier inventory: An empirical implementation model", International Journal of Production Research 27/12, pp. 1993-2007, 1989.

[4]. Dempsey, W.A., "Vendor selection and the buying process", Industrial Marketing Management 7, pp. 257-267, 1978.

[5]. Dickson, G.W., "An analysis of vendor selection systems and decisions", Journal of Purchasing 2/1, pp. 5-17, 1966.

[6]. Hakansson, H., \& Wootz, B., "Supplier selection in an international environment - An experimental study", Journal of Marketing Research XII, pp. 46-51, 1975.

[7]. Karmarker, U. S., "Capacity loading, and release planning with work-in-progress (WIP) and lead-time", Journal of Manufacturing Operations Management, vol. 2, pp. 105-123, 1989.

[8]. Monczka, R.M., \& Trecha, S.J., "Cost-based supplier performance evaluation", Journal of Purchasing and Materials Management, pp. 2-7, 1998.

[9]. Monczka R. M., Petersen, K. J., Handfield, R. B., \& Ragatz, G. L., "Success factors in strategic supplier alliances: The buying company perspective", Production and Inventory Management Journal, 29 (3), pp. 553-578, 1998. 
